\title{
Comparison of serum copper, chromium and selenium concentrations in diabetic and nondiabetic population and their association with glycated hemoglobin levels
}

\author{
Shaik Fayazul Haq ${ }^{1}$, Busi Karunanand ${ }^{2 *}$, Kamla Pati Mishra ${ }^{1}$, Dinesh Kumar Sharma ${ }^{2}$, Ajit Singh ${ }^{2}$ \\ ${ }^{1}$ Department of Biochemistry, Shree Guru Gobind Singh Tricentenary University, Gurugram, India. \\ ${ }^{2}$ National Director for Research, World Youth Heart Federation (WYHF) - India.
}

\section{ARTICLE INFO \\ Received on: 29/03/2020 \\ Accepted on: 10/12/2020 \\ Available online: 05/02/2021}

\section{Key words:}

Trace elements, micronutrients, diabetes mellitus, oxidative stress, diabetic complications.

\begin{abstract}
Introduction: The microelements are an integral component of glucose homeostasis and other catalytic reactions. Serum concentrations of various micronutrients are associated with glycosylated hemoglobin (HbAlc) levels and complications of diabetes.

Methodology: The present study compares the serum concentrations of copper $(\mathrm{Cu})$, chromium $(\mathrm{Cr})$, and selenium (Se) in diabetic patients and nondiabetic control subjects and also investigated the association of serum $\mathrm{Cu}, \mathrm{Cr}$, and $\mathrm{Se}$ concentrations with HbA1c levels.

Results: The study population included 126 cases and 126 controls in a 1:1 ratio with the mean age of 56 years. Auto analyzers analyzed trace elements and $\mathrm{HbAlc}$ with the standard procedures. Lipid levels, including total cholesterol, high and low-density lipids, were statistically significantly high in diabetic patients than control subjects (p-value $<0.05)$. Copper showed high concentration in diabetic patients in comparison to nondiabetic controls $(133.86 \pm 10.37$ vs. $97.6 \pm 13.02 \mathrm{mcg} / \mathrm{dL} ; p$-value $<0.001)$ and $\mathrm{Cr}$ and Se showed low concentrations in diabetics in comparison to non-diabetics $(0.134 \pm 0.044$ vs. $0.169 \pm 0.072 \mathrm{mcg} / \mathrm{L} ; p$-value $<0.001$ and $65.83 \pm 18.26 v s .120 .82 \pm 21.09 \mathrm{ng} / \mathrm{mL}$; $p$-value $<0.001$ respectively).

Conclusion: The serum concentration of $\mathrm{Cu}$ increases with the increased levels of $\mathrm{HbA1c}$, Serum creatinine, and $\mathrm{Se}$ concentrations proportionally decrease with increased $\mathrm{HbAlc}$ levels.
\end{abstract}

\section{INTRODUCTION}

The rising incidence of diabetes mellitus (DM) is one of the main health issues; the number of diabetic patients is increasing throughout the world, and it is estimated that around 592 million people would have diabetes by 2,035 (Forouhi and Wareham, 2014). $\mathrm{DM}$ is a cumulative effect of low insulin secretion, or impaired action of insulin, reduced glucose utilization, and increased glucose production, depending on the type of diabetes. Chronic hyperglycemia is associated with multiple system dysfunction and long-term endorgan damage (American Diabetes Association, 2020).

"Corresponding Author

Busi Karunanand, Department of Biochemistry, Shree Guru

Gobind Singh Tricentenary University, Gurugram, India.

E-mail: karunanandbusi@gmail.com
The microelements are an integral component of glucose homeostasis, antioxidant enzymes, lipid metabolism, and potential pro-oxidant catalysts. In DM patients, complications arise because of responsible factors such as increased oxidative stress, production of free radicals, and protein glycosylation (Makhlough et al., 2015; Mohammed et al., 2018). Copper (Cu) is a pro-oxidant factor; its deficiency leads to glucose intolerance, diminished insulin response, and increased glucose response. Evidence suggests that $\mathrm{Cu}$ ions have more affinity to bind protein glycosylation, which causes an oxidative reaction, increased oxidative stress, and free radical production in diabetes (Sarkar et al., 2010). Chromium (Cr) helps in the binding of insulin to cells by increasing the number of insulin receptors and glucose utilization and beta-cell activity. Sufficient dietary intake of $\mathrm{Cr}$ reduces the requirement of insulin (Mohamed et al., 2019). Selenium (Se) is another microelement that acts as a cofactor along with glutathione peroxidase, which is an antioxidant 
enzyme and helps in dropping the formation of free radicals and peroxides of lipoproteins. Lower Se serum levels can be seen in diabetic patients and they increase the risk of hypertension and coronary artery disease (Eva et al., 2017; Wei et al., 2015).

Glycated hemoglobin is essential in the pathogenesis of diabetic vascular complications. The serum concentration of various micronutrients is associated with glycosylated hemoglobin (HbA1c) levels and leads to diabetic complications (Atari-Hajipirloo et al., 2016). However, the assessment of microelements such as Se in diabetic patients remains conflicting with a lot of unanswered questions (Riaz et al., 2014). The present study aims to measure the serum concentration of three microelements $(\mathrm{Cu}, \mathrm{Cr}$, and $\mathrm{Se})$ in $\mathrm{DM}$ patients. The study also compares the serum concentration of these microelements in diabetic patients and nondiabetic controls. Vague results of studies establishing the association between $\mathrm{HbAlc}$ and serum $\mathrm{Cu}, \mathrm{Cr}$, and $\mathrm{Se}$ concentrations (Atari-Hajipirloo et al., 2016; Unjiati and Adriani, 2015) are found in the literature. Also, we are assessing the correlation of serum $\mathrm{Cu}, \mathrm{Cr}$, and Se concentrations with $\mathrm{HbA} 1 \mathrm{c}$ levels.

\section{METHODS}

\section{Study population}

The study was carried out on 252 subjects comprising 126 diabetic patients (Cases) and 126 healthy subjects (nondiabetic) (Controls) matched for age and sex. The age was varied from 35 to 65 years with a median age of 53 years. The team decided to keep $30 \%-40 \%$ of females in each group based on the statistics available about the gender-specific patient distribution at the study site. The sample size was calculated using a specified software for an independent case-control approach based on the proportions representing the group's exposure. This study was performed at Shree Guru Gobind Singh Tricentenary University, Haryana, from September 2013 to August 2018. The subjects and patients were recruited by convenience sampling method based on the availability and willingness to participate. In the control group, healthy individuals from the general population without diabetes or any other comorbidity or complications were taken. Type 2 DM patients with matched age and gender without any other comorbidities were included in the case group.

The exclusion criteria for the case group were pregnant and lactating women, chronic alcoholics, patients taking drugs such as steroids, hormonal, and micronutrient supplements, patients having liver and kidney diseases, and patients with known cases of epilepsy, migraine, or other chronic illness.

After recruiting the patients and healthy subjects as per the inclusion and exclusion criteria, blood samples were collected for specific tests, which are described in the next section.

\section{Ethical consideration}

Ethical confirmation was obtained from the Institutional Ethical Committee of Shree Guru Gobind Singh Tricentenary University, Haryana, before the commencement of the study. Currently, the study is being continued with the recently revised ethical approval number IEC/FMHS/F/21/09/18/02. All subjects in this study were recruited after obtaining informed consent and complete history, and a thorough clinical examination was done.

\section{Trace elements and HbA1c analysis}

Five milliliters $(\mathrm{ml})$ of venous blood were collected from the antecubital vein using a disposable needle and syringe after overnight fasting for all the cases and controls. The blood sample was centrifuged at 4,000 rpm for 10 minutes, and serum was separated and stored in a deep-freezer at $-80^{\circ} \mathrm{C}$. Immediately after separating plasma, each sample was diluted with glycerol. Levels of Serum $\mathrm{Cu}, \mathrm{Cr}$, and Se were investigated using an auto-analyzer atomic absorption spectrometer. The calibration curve was plotted to know the serum concentration of all metals for each sample.

Glycosylated hemoglobin was analyzed using Immunoturbidity Enhance Enzymatic method and was done in a fully automated analyzer (BS-300).

\section{Statistical analysis}

Baseline characteristics were presented as proportions for categorical variables, and continuous variables were presented as mean \pm standard deviation. Statistical differences between each parameter of the diabetic and control groups were evaluated for significance by independent $T$-test and Chi-square test. Concentration differences of serum microelements between diabetic and nondiabetic populations were presented using Boxplots. Scatter-plots are used to present the correlation between serum microelement concentration and $\mathrm{HbAlc}$ level. The $p$-value $<0.05$ was considered for significant results. The data were analyzed using Statistical Package for the Social Sciences 22.0 statistical analysis software.

\section{RESULTS}

\section{Baseline socio-demographic and clinical parameters}

The study population included 126 cases and 126 controls in a 1:1 ratio to compare the concentration of microelements. Socio-demographic data and clinical findings of both case and control groups are presented with the significance. Diabetic patients showed a high proportion of dyslipidemia $(p<0.001)$ than nondiabetics. Baseline laboratory and vital parameters were assessed in both the study groups (Table 1).

\section{Trace elements in diabetic and nondiabetics}

The serum concentrations of microelements were compared in both the cases and controls (Table 2). Mean serum $\mathrm{Cu}$ concentration was statistically high in diabetic patients than in healthy individuals $(p<0.001)$ (Fig. 1). The mean serum $\mathrm{Cr}$ and Se concentrations were low in diabetic patients than in healthy individuals, and the difference between case and control was statistically significant $(p<0.001)$ (Figs. 2 and 3).

\section{HbA1c and microelements}

We have observed in our study subjects that the serum concentration of $\mathrm{Cu}$ increases with the increased levels of $\mathrm{HbAlc}$ (Fig. 4). Nondiabetic patients have had normal HbAlc level $(<6.5 \%)$, and serum $\mathrm{Cu}$ concentrations were $<120 \mathrm{mcg} / \mathrm{dl}$. Serum $\mathrm{Cr}$ concentration proportionally decreases with increased $\mathrm{HbA} 1 \mathrm{c}$ level (Fig. 5). The serum concentration of Se was high in patients with normal $\mathrm{HbAlc}$ and decreases in patients with chronic abnormal HbAlc level (Fig. 6). 
Table 1. Baseline socio-demographic and clinical characteristics of diabetic and nondiabetic groups.

\begin{tabular}{lccc}
\hline Parameters & Diabetic $(\boldsymbol{n}, \mathbf{1 2 6})$ & Non-diabetic $(\boldsymbol{n}, \mathbf{1 2 6})$ & $\boldsymbol{p}$-value \\
\hline Age & $53.94 \pm 7.82$ & $53.87 \pm 4.92$ & 0.939 \\
Gender & & & \\
$\quad$ Male & $77(61.1 \%)$ & $86(68.3 \%)$ & 0.146 \\
$\quad$ Female & $49(38.9 \%)$ & $40(31.7 \%)$ & \\
Social habits & & & 0.448 \\
$\quad$ Smoking & $48(38.1 \%)$ & $46(36.5 \%)$ & 0.003 \\
$\quad$ Alcoholic & $21(16.7 \%)$ & $41(32.5 \%)$ & \\
Clinical history & & & 0.259 \\
$\quad$ Family history of diabetes & $26(20.6 \%)$ & $21(16.7 \%)$ & $<0.001$ \\
$\quad$ Dyslipidemia & $33(26.2 \%)$ & 0.041 \\
Body mass index (kg/m²) & $100(79.4 \%)$ & $23.25 \pm 1.90$ & 0.122 \\
Systolic blood pressure (mmHg) & $23.94 \pm 3.30$ & $123.32 \pm 5.85$ & 0.669 \\
Diastolic blood pressure (mmHg) & $126.24 \pm 6.72$ & $86.62 \pm 61.96$ & $<0.001$ \\
Glycated hemoglobin (\%) & $84.25 \pm 3.80$ & $5.32 \pm 1.34$ & $<0.001$ \\
Total cholesterol (mg/dl) & $9.20 \pm 2.61$ & $167.5 \pm 11.16$ & $<0.001$ \\
Triglycerides (mg/dl) & $196.10 \pm 25.00$ & $131.07 \pm 10.50$ & $<0.001$ \\
High density lipids (mg/dl) & $223.75 \pm 47.68$ & $51.72 \pm 5.43$ & 0.015 \\
Low density lipids (mg/dl) & $42.02 \pm 6.07$ & $99.02 \pm 13.33$ & $<0.001$ \\
Very low density lipids (mg/dl) & $93.50 \pm 21.43$ & $35.55 \pm 5.69$ & \\
\hline
\end{tabular}

${ }^{a}$ Dyslipidemia defined as total cholesterol $>250 \mathrm{mg} / \mathrm{dl}$, Low density lipids (LDL) $>130 \mathrm{mg} / \mathrm{dl}$, and High density lipids (HDL) $<40 \mathrm{mg} / \mathrm{dl}(<50 \mathrm{mg} / \mathrm{dl}$ for women) in the fasting state.

Table 2. Comparison of Crchromium, Cucopper, and Seselenium in diabetic and nondiabetic groups.

\begin{tabular}{cccc}
\hline Trace elements & Diabetic $(\boldsymbol{n}, \mathbf{1 2 6})$ & Non-diabetic $(\boldsymbol{n}, \mathbf{1 2 6})$ & $\boldsymbol{p}$-value \\
\hline $\mathrm{Cr}(\mathrm{mcg} / \mathrm{dl})$ & $0.134 \pm 0.044$ & $0.169 \pm 0.072$ & $<0.001$ \\
$\mathrm{Cu}(\mathrm{mcg} / \mathrm{l})$ & $133.86 \pm 10.37$ & $97.6 \pm 13.02$ & $<0.001$ \\
$\mathrm{Se}(\mathrm{ng} / \mathrm{ml})$ & $65.83 \pm 18.26$ & $120.82 \pm 21.09$ & $<0.001$ \\
\hline
\end{tabular}

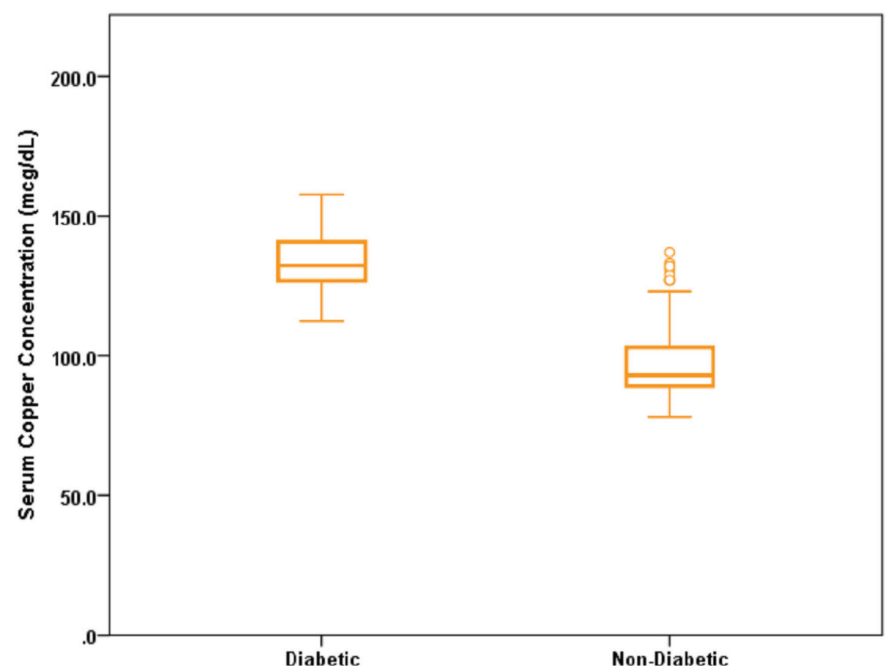

Figure 1. Box-plot showing the concentration of serum Cucopper in diabetic and nondiabetic individuals.

\section{DISCUSSION}

In the present study, we have observed a higher level of serum $\mathrm{Cu}$ and lower levels of serum $\mathrm{Cr}$ and $\mathrm{Se}$ in diabetic

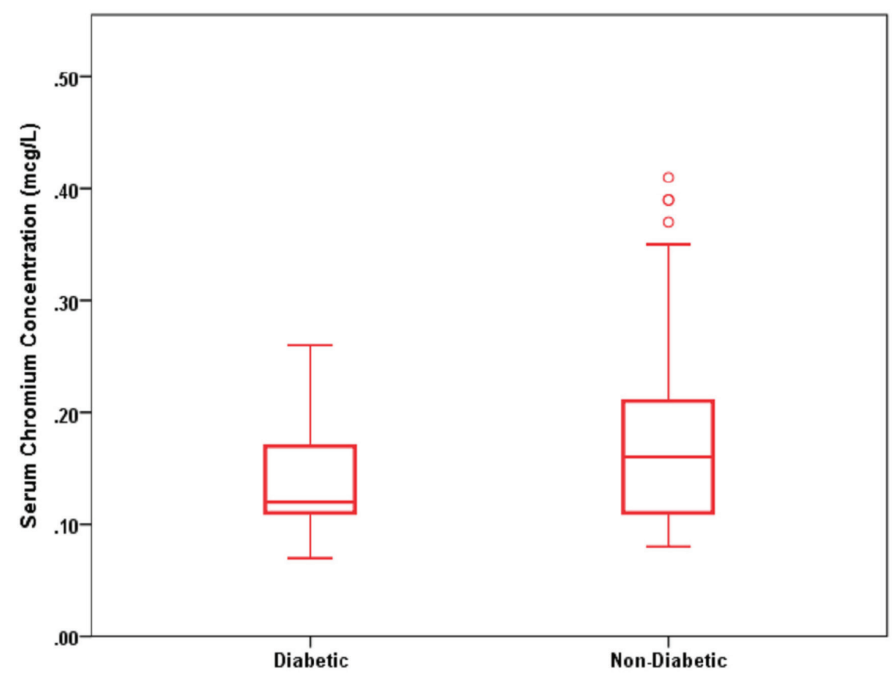

Figure 2. Box-plot showing the concentration of serum Crchromium in diabetic and nondiabetic individuals.

patients compared with the control subjects. Our observations also demonstrated a significant difference in the serum concentration of the studied microelements in both diabetic and healthy subjects. 


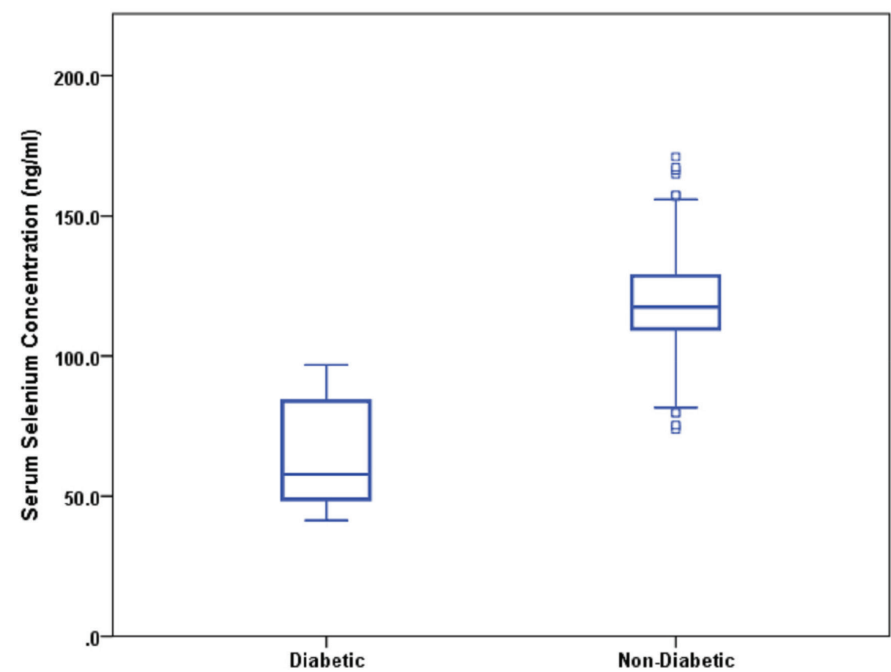

Figure 3. Box-plot showing the concentration of serum Seselenium in diabetic and nondiabetic individuals.

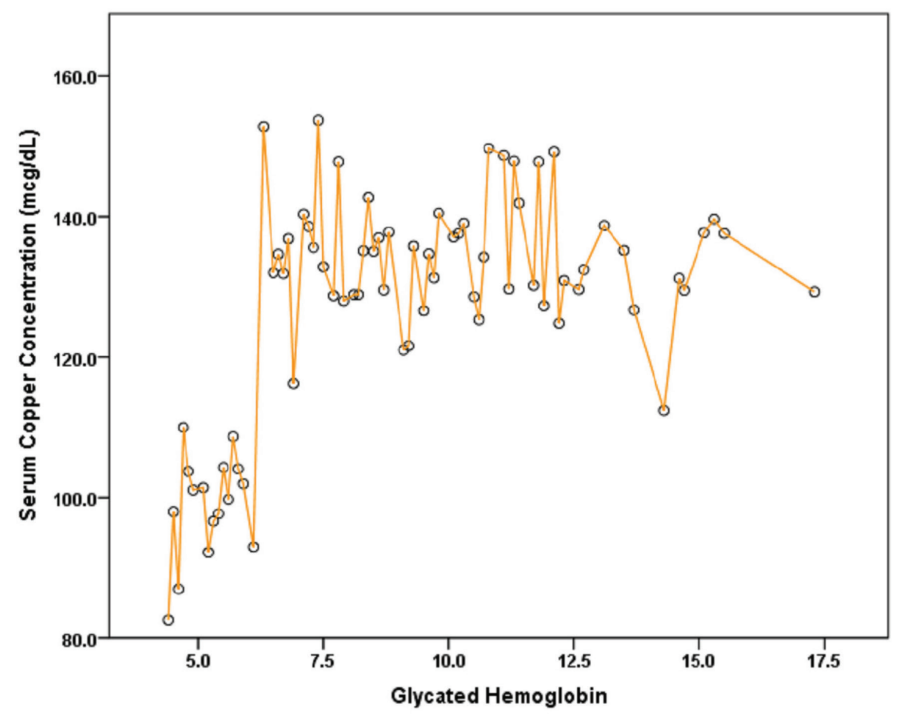

Figure 4. Scattered plot showing the correlation between serum Cucopper concentration and glycated hemoglobin.

We also correlated the serum concentration of the microelements with $\mathrm{HbAlc}$ in all participants. The significant distribution differences were noted in serum levels of $\mathrm{Cu}, \mathrm{Cr}$, and Se in patients with normal and high $\mathrm{HbAlc}$ levels.

Macro and microelements play a major role in the growth and metabolism and are also involved in the development of secondary complications of DM (Mahdizadeh et al., 2014).

Various studies have reported that the change in concentration of microelements might be a contributing factor in the pathogenesis of diabetes. The imbalance in the metabolism of some microelements adversely affects pancreatic islet and causes diabetes. Furthermore, microelements imbalance increased the generation of some reactive oxygen species (ROS) and hyperglycemia causes oxidative stress (Abou-Seif and Youssef, 2004). Earlier studies showed the involvement of $\mathrm{Cu}$, causing oxidative stress (Saha-Roy et al., 2014).

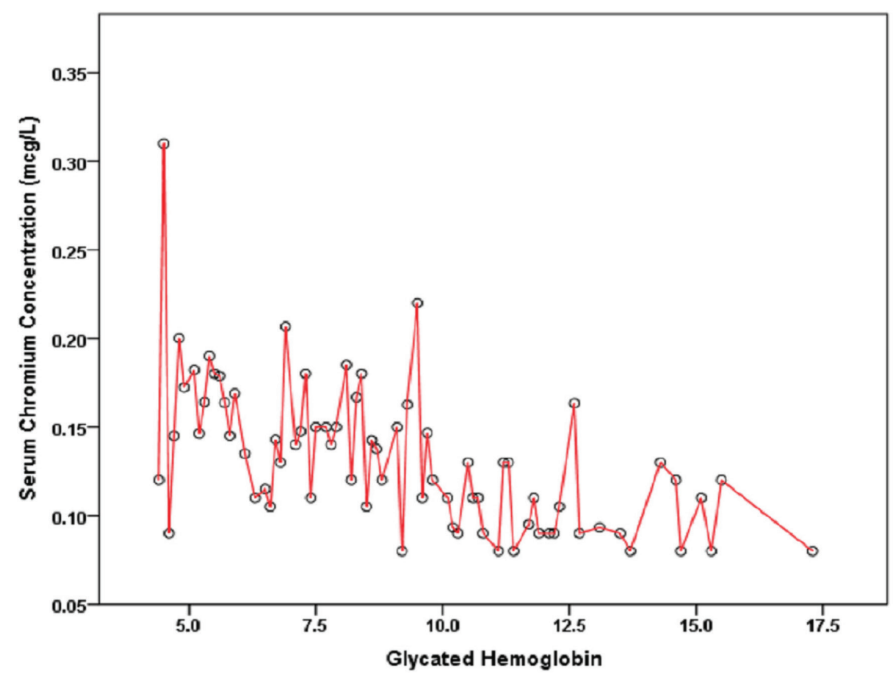

Figure 5. Scattered plot showing the correlation between serum Crchromium concentration and glycated hemoglobin.

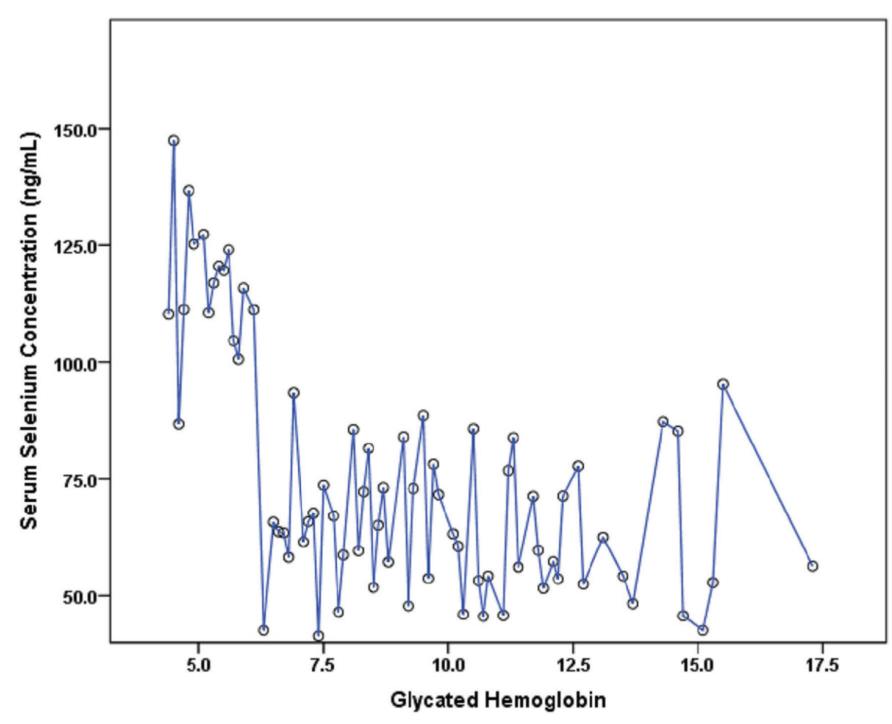

Figure 6. Scattered plot showing the correlation between serum Seselenium concentration and glycated hemoglobin.

Furthermore, generate ROS and free radicals by active participation in Heiber--Weiss and Fenton reactions. In diabetic patients, $\mathrm{Cu}$ is involved in glycation and its stimulation and causes the release of $\mathrm{Cu}$ ions from $\mathrm{Cu}$-binding sites. These $\mathrm{Cu}$ ions release into the blood and enhance glycation for end products (Babalola et al., 2007). These glycation end products play a role in the pathogenesis and progression of diabetic complications. In this study, we have analyzed that the serum concentration of $\mathrm{Cu}$ was significantly higher in diabetic patients than in healthy individuals. Studies evaluating serum zinc and $\mathrm{Cu}$ levels in DM patients showed higher $\mathrm{Cu}$ levels in diabetic patients (with and without complications) than the controls (Devi et al., 2016; Nagarajrao and Alharbi, 2015; Zargar et al., 1998).

$\mathrm{Cr}$ is an essential microelement and possesses anti-diabetic effect. It helps in improving fasting blood sugar, insulin function, and insulin-receptor binding properties. $\mathrm{Cr}$ causes pancreas beta- 
cell sensitivity and glucagon action (Mohamed et al., 2019). It acts by enhancing the effect of insulin by increasing the number of insulin receptors and binding (Rafi and Narayana, 2019). Our observations showed a low serum concentration of $\mathrm{Cr}$ in diabetic patients $(p<0.001)$ than in healthy subjects. A prior study showed the association of $\mathrm{Cr}$ levels and glycemic control and reported that mean serum $\mathrm{Cr}$ concentration was significantly lower $(p<0.05)$ in uncontrolled type 2 diabetic patients (Rajendran et al., 2015). Another study compared the levels of plasma $\mathrm{Cr}$ and urine $\mathrm{Cr}$ in non-insulin-dependent DM patients and found that plasma $\mathrm{Cr}$ was lower by $33 \%$ and urine $\mathrm{Cr}$ higher by $100 \%$ in their patients. The investigator showed that plasma $\mathrm{Cr}$ was inversely correlated with plasma glucose during the onset of diabetes (Sutiari et al., 2017).

The present study showed significantly low serum Se concentration in diabetic patients than in healthy subjects ( $p$ $<0.001)$. The third National Health and Nutrition Examination Survey (NHANES III) and NHANES 2003-2004 both showed a positive correlation between serum $\mathrm{Se}$ and the prevalence of diabetes (Laclaustra et al., 2009). Serum Se levels in uncomplicated DM patients showed similar results (Riaz et al., 2014). Another investigator evaluated the correlation of dietary Se with diabetes in middle-aged and older Chinese adults and showed that the average dietary Se intake level is $43.51 \mu \mathrm{g} /$ days among middle-aged and elderly adults. There was a significant positive association between dietary Se intake and serum levels in diabetic patients $(p=0.03)$ (Wei et al., 2015).

In the present study, we have observed a significant positive correlation between serum $\mathrm{Cu}$ and $\mathrm{HbA} 1 \mathrm{c}$ in both diabetic and healthy subjects. In contrast, serum $\mathrm{Cr}$ and Se decreased with an increase in $\mathrm{HbAlc}$ in diabetic patients than healthy individuals. A study analyzed the association between $\mathrm{HbAlc}$ and levels of microelements in DM patients and control subjects. The investigator observed that $\mathrm{HbAlc}$ levels were positively correlated with $\mathrm{Cu}$ in patients with DM ( $p<0.05)$ (Atari-Hajipirloo et al., 2016). Some researchers have reported their hypothesis that binding of transition metals (CU and $\mathrm{Fe}$ ) with glycated proteins may result in glycocholate formation (Naka et al., 2013). Other than this, it is known that at a high glucose concentration, $\mathrm{Cu}$ ion is released, zincsuperoxide dismutase, which may explain the mechanism of how serum $\mathrm{Cu}$ level increased under diabetic conditions (Viktorínová et al., 2009). Cr has shown an inverse linear correlation with the HbAlc level (Rajendran et al., 2015; Unjiati and Adriani, 2015). However, the association of microelements with HbAlc should be evaluated to understand the exact mechanisms better.

\section{Strengths of the study}

The study compares the serum concentrations of trace elements between healthy controls and patients with DM and establishes an association of these concentrations with $\mathrm{HbA1c}$ level. Based on the HbAlc level, clinicians can predict micronutrient deficiencies and related complications in diabetic patients and vice versa. The study also included the participant with matched characteristics (age and gender ratio) in both groups. One of the major significance of this study was its exclusion criteria. We have excluded all the patients or healthy subjects with any other comorbidity to avoid the confounders and getting the relevant results. This is also one of the rare studies that assessed the correlation between Se serum concentration and HbAlc level.

\section{Limitations of the study}

Micronutrient deficiency and serum concentration are associated with dietary alterations in both healthy subjects and DM patients. This study did not measure the dietary consumption of trace elements in any study group, so it could not establish any relationship between serum concentrations and $\mathrm{HbA1c}$ level.

\section{CONCLUSION}

The study demonstrated the significant difference between serum concentrations of all three microelements $(\mathrm{Cu}$, $\mathrm{Cr}$, and $\mathrm{Se}$ ) among diabetic patients and control subjects. The difference in $\mathrm{Cu}$ and $\mathrm{Cr}$ levels between cases and controls may play a crucial role in the pathogenesis of this disease as these metals involve in the oxidative stress response. The study also observed that increased levels of $\mathrm{Cu}$ and decreased levels of $\mathrm{Cr}$ and $\mathrm{Se}$ were associated with the increased value of $\mathrm{HbA} 1 \mathrm{c}$ in diabetic patients. Further studies to find an association and to avoid/delay the complications by dietary alterations of microelements in diabetic patients are recommended.

\section{ACKNOWLEDGMENTS}

The authors want to thank the laboratory facilities of King George's Medical University, Lucknow, Uttar Pradesh, for their support in analyzing trace elements.

\section{AUTHORSHIP CONTRIBUTION}

All the authors are eligible to be an author as per the international committee of medical journal editors (ICMJE) requirements/guidelines.

\section{CONFLICT OF INTEREST}

The authors do not declare any conflict of interest.

\section{FUNDING}

The study did not get any external funding.

\section{ETHICAL APPROVALS}

The study is being continued with the recently revised ethical approval number IEC/FMHS/F/21/09/18/02.

\section{PUBLISHER'S NOTE}

This journal remains neutral with regard to jurisdictional claims in published institutional affiliation.

\section{REFERENCES}

Abou-Seif MA, Youssef AA. Evaluation of some biochemical changes in diabetic patients. Clin Chim Acta, 2004; 346(2):161-70.

American Diabetes Association. Classification and diagnosis of diabetes: standards of medical care in diabetes - 2020. Diabetes Care, 2020; 43(S1):S14-31.

Atari-Hajipirloo S, Valizadeh N, Khadem-Ansari MH, Rasmi Y, Kheradmand F. Altered concentrations of copper, zinc, and iron are associated with increased levels of glycated hemoglobin in patients with type 2 diabetes mellitus and their first-degree relatives. Int J Endocrinol Metab, 2016; 14(2):1-7.

Babalola OO, Ojo LO, Akinleye AO. Status of the levels of lead and selected trace elements in type 2 diabetes mellitus patients in Abeokuta, Nigeria. Afr J Biochem Res, 2007; 1(7):127-31.

Devi TR, Hijam D, Dubey A, Debnath S, Oinam P, Devi NT, Singh WG. Study of serum zinc and copper levels in type 2 diabetes mellitus. Int J Contemp Med Res, 2016; 3(4):1036-40. 
Eva H, Akhter QS, Alam MK, Ahmed S. Serum chromium and selenium levels in type 2 diabetes mellitus. J Bangladesh Soc Physiol, 2017; 12(2):72-5.

Forouhi NG, Wareham NJ. Epidemiology of diabetes. Medicine (Abingdon), 2014; 42(12):698-702.

Laclaustra M, Navas-Acien A, Stranges S, Ordovas JM, Guallar E. Serum selenium concentrations and diabetes in US adults: national health and nutrition examination survey (NHANES) 2003-2004. Environ Health Perspect, 2009; 117(9):1409-13.

Mahdizadeh R, Shirali S, Ebadi P. Investigation of imbalance of trace elements in patients with type 2 diabetes mellitus. J Acad Appl Stud, 2014; 4(9):11-21.

Makhlough A, Makhlough M, Shokrzadeh M, Mohammadian M, Sedighi O, Faghihan M. Comparing the levels of trace elements in patients with diabetic nephropathy and healthy individuals. Nephrourol Mon, 2015; 7(4):e28576.

Mohamed HM, Sadik IM, Eltom A, Osman AL, Babker AM. A study of correlation of serum chromium level with glycosylated haemoglobin $(\mathrm{HbA} 1 \mathrm{c})$, total cholesterol and triglycerides, among type 2 diabetes patients. Open J Blood Dis, 2019; 9(1):1-8.

Mohammed RR, Mehrez MM, Abdel-Maksoud H. Biochemical relations between copper, selenium, zinc, and magnesium with the glycemic state of diabetic pregnant women. Benha Med J, 2018; 35(3):344.

Nagarajrao R, Alharbi SA. Evaluation of serum zinc, copper, magnesium and iron levels in type 2 diabetes mellitus patients. Int $\mathrm{J}$ Adv Res, 2015; 3(2):960-5.

Naka T, Kaneto H, Katakami N, Matsuoka TA, Harada A, Yamasaki Y, Matsuhisa M, Shimomura I. Association of serum copper levels and glycemic control in patients with type 2 diabetes. Endocr J, 2013; 60(3):393-6.

Rafi M, Narayana SL. A study of chromium levels in type 2 diabetes mellitus. Int J Med Health Res, 2019; 5(6):126-30.

Rajendran K, Manikandan S, Nair LD, Karuthodiyil R, Vijayarajan N, Gnanasekar R, Kapil VV, Mohamed AS. Serum chromium levels in type 2 diabetic patients and its association with glycaemic control. J Clin Diagn Res, 2015; 9(11):OC05.

Riaz M, Mahmood KT, Irfan K. Serum levels of selenium in uncomplicated type-2 diabetic patients and healthy individuals. Int J Pharm Sci Res, 2014; 5(10):4219.
Saha-Roy S, Pal S, Bera S, Choudhury KM, Bhattacharya A, Sen G, Gupta S. Status of serum magnesium, zinc \& copper in patients suffering from type-2 diabetes mellitus. J Drug Deliv Ther, 2014; 4(1):70-2.

Sarkar A, Dash S, Barik BK, Muttigi MS, Kedage V, Shetty JK, Prakash M. Copper and ceruloplasmin levels in relation to total thiols and GST in type 2 diabetes mellitus patients. Indian J Clin Biochem, 2010; 25(1):74-6.

Sutiari NK, Rimbawan R, Kusharto CM, Purwatyastuti, Effendi AT. Glycated hemoglobin (Hbalc), blood glucose, and chromium levels among type 2 diabetic patients: a cross-sectional study in Denpasar, Bali. Int J Sci Basic Appl Res, 2017; 2(36):135-44.

Unjiati WB, Adriani M. Chromium and zinc level of patients with type 2 diabetes and non-diabetes. Biochem Physiol, 2015; 5:2.

Viktorínová A, Tošerová E, Križko M, Duračková Z. Altered metabolism of copper, zinc, and magnesium is associated with increased levels of glycated hemoglobin in patients with diabetes mellitus. Metabolism, 2009; 58(10):1477-82.

Wei J, Zeng C, Gong QY, Yang HB, Li XX, Lei GH, Yang TB. The association between dietary selenium intake and diabetes: a crosssectional study among middle-aged and older adults. Nutr J, 2015; 14(1):18.

Zargar AH, Shah NA, Masoodi SR, Laway BA, Dar FA, Khan AR, Sofi FA, Wani AI. Copper, zinc, and magnesium levels in non-insulin dependent diabetes mellitus. Postgrad Med J, 1998; 74(877):665-8.

\section{How to cite this article:}

Haq SF, Karunanand B, Mishra KP, Sharma DK, Singh A. Comparison of serum copper, chromium and selenium concentrations in diabetic and nondiabetic population and their association with glycated hemoglobin levels. J Appl Pharm Sci, 2021; 11(02):046-051. 